Research Article

\title{
Determinants of Anemia among Children Aged 6-59 Months in Ethiopia: Further Analysis of the 2016 Ethiopian Demographic Health Survey
}

\author{
Melash Belachew Asresie $(\mathbb{D}$, Gedefaw Abeje Fekadu (D), and Gizachew Worku Dagnew (D) \\ Department of Reproductive Health and Population Studies, School of Public Health, College of Medicine and Health Science, \\ Bahir Dar University, Bahir Dar, Ethiopia \\ Correspondence should be addressed to Melash Belachew Asresie; kalleab1@gmail.com
}

Received 2 June 2019; Revised 18 January 2020; Accepted 23 January 2020; Published 9 March 2020

Academic Editor: Carol J. Burns

Copyright (c) 2020 Melash Belachew Asresie et al. This is an open access article distributed under the Creative Commons Attribution License, which permits unrestricted use, distribution, and reproduction in any medium, provided the original work is properly cited.

\begin{abstract}
Background. Anemia among children is a global public health problem. The burden is high in developing countries including Ethiopia. Although there are some studies about anemia among children, there is a dearth of information about factors associated with anemia in Ethiopia. Therefore, this analysis was performed to identify factors associated with anemia among children aged 6-59 months in Ethiopia. Methods. We used the 2016 Ethiopian Demography and Health Survey (EDHS) data. EDHS was a community-based, cross-sectional study conducted from January 18, 2016 to June 27, 2016. The 2016 EDHS selected the participants using a two-stage stratified cluster sampling technique. A total of 8,462 children aged 6-59 months were included for this analysis. Both descriptive and logistic regression analyses were performed using Stata version 14 . A $P$ value less than 0.05 at 95\% confidence interval was set to test the statistical significance. Results. The analysis indicated that about 58\% (95\% CI: 55.1, 60.1) of children aged 6-59 months were anemic. Of those, $29.4 \%$ and $3.1 \%$ had moderate and severe anemia, respectively. The analysis revealed that stunted $(\mathrm{AOR}=0.135,95 \% \mathrm{CI}: 1.13,1.62)$ and underweight $(\mathrm{AOR}=1.27,95 \% \mathrm{CI}: 1.04,1.55)$ children had higher odds of being anemic. Besides, children aged 6-23 months (AOR=1.39, 95\% CI: 1.06, 1.82), 24-42 months of age $(\mathrm{AOR}=1.26,95 \% \mathrm{CI}: 1.05,1.51)$, and those with fever $(\mathrm{AOR}=1.34,95 \% \mathrm{CI}: 1.07,1.67)$ had higher odds of being anemic. Similarly, children from anemic mothers $(\mathrm{AOR}=1.86,95 \% \mathrm{CI}: 1.58,2.18)$ and poor households $(\mathrm{AOR}=1.35,95 \% \mathrm{CI}: 1.09,1.67)$ were at a higher risk of anemia. Children from households with large family sizes (AOR $=1.29,95 \%$ CI: 1.03, 1.60), young mothers $(15-24$ years of age $(\mathrm{AOR}=1.39,95 \% \mathrm{CI}: 1.06,1.82)$ and $25-34$ years of age $(\mathrm{AOR}=1.26,95 \% \mathrm{CI}: 1.05,1.51)$ ), and developing regions $(\mathrm{AOR}=1.44,95 \% \mathrm{CI}: 1.03,2.02)$ also had higher odds of developing anemia. Conclusion. The overall prevalence of anemia among children aged 6-59 months in Ethiopia was high. Malnourished children (stunting and underweight); children with fever; children from anemic, uneducated, and young mothers; and children from large and poor families had higher odds to develop anemia. Therefore, preventing childhood illnesses and maternal anemia should be strengthened to reduce anemia among children.
\end{abstract}

\section{Background}

Anemia among children is a public health problem globally [1-3]. An estimated 273.2 million children aged 6-59 months suffer from anemia globally. Sub-Saharan Africa was the most affected, with a prevalence of $62.3 \%$ [4]. The World Health Organization (WHO) reflects if anemia prevalence is over $40 \%$ in the community, considering it as a major public health problem [2]. Anemia has negative effects on physical development, attentiveness, memory, and academic performance of children [5, 6]. Many factors affect the development of anemia among children aged 6-59 months. Inadequate iron and vitamin $[7,8]$; sociodemographic characteristics of mothers' households such as region, wealth index, and water source; mothers' current working status; maternal anemia status; and child characteristics (age, nutritional status, and size of children at birth) $[9,10]$ are the most significant factors for anemia among children.

Surveys in Ethiopia reported that anemia among children is a public health problem $[11,12]$, but studies to 
identify the determinants of anemia among children are limited. This analysis was therefore done to identify factors associated with anemia among children aged 6-59 months in Ethiopia using the 2016 Ethiopian Demographic Health Survey (EDHS) data.

\section{Methods and Material}

We used the 2016 EDHS data, collected from all administrative regions' city administrations. EDHS was a crosssectional community-based survey conducted from January 18, 2016 to June 27, 2016. The data were collected by the Central Statistical Agency (CSA) at the request of the Federal Ministry of Health (FMOH).

The 2016 EDHS used a two-stage stratified cluster sampling technique to ensure representativeness at national and regional levels. Initially, each region was stratified into urban and rural areas, yielding 21 sampling strata. Each stratum was subdivided into enumeration areas. After stratification, a total of 645 enumeration areas (202 in urban areas and 443 in rural areas) were selected with probability proportional to enumeration area size based on the 2007 Ethiopia population and housing census. A household listing operation was carried out in all the selected enumeration areas from September to December 2015. Then, 28 households from each cluster were selected using the systematic random sampling technique from the household listing.

Data about the health status of children were collected when the enumerators identified children in the selected households. Anemia testing was performed on children aged 6-59 months when parents or caretakers consented to the test. Blood samples were drawn using a finger prick or a heel prick in the case of children aged 6-11 months. Hemoglobin analysis was done on site using a battery-operated portable HemoCue analyzer [13]. In this analysis, 8,462 6-59-monthold children were included for the final analysis.

\section{Measurements}

3.1. Outcome Variable. Anemia status among children aged 6-59 months was the outcome variable. According to the WHO criteria, children aged 6-59 months are considered anemic if their hemoglobin level is below $11.0 \mathrm{~g} / \mathrm{dl}$. It was further classified as mild $(10.0-10.9 \mathrm{~g} / \mathrm{dl})$, moderate $(7.0-9.9 \mathrm{~g} / \mathrm{dl})$, and severe $(<7.0 \mathrm{~g} / \mathrm{dl})$.

3.2. Explanatory Variables. Residence (urban and rural), region (developing and major city administrative), mother's age (15-24, 25-34, and 35-49 years), mothers' education status (no education, primary, and secondary or above), mother's anemia status (no anemic and anemic), mother's occupation (working or not working outside home at the time of survey), mother's marital status (married and not married), family size $(\leq 4,5-8$, and $\geq 9)$, mother's body mass index (BMI) $\left(<18.5 \mathrm{~kg} / \mathrm{m}^{2}\right.$ and $\left.18.5 \mathrm{~kg} / \mathrm{m}^{2}\right)$, source of drinking water (not improved and improved), wealth index (poor, middle, and rich), types of toilet (not improved and improved), number of living under-five children (3 or less or 4 or more), sex of the child (female and male), birth order (5 or less or 5 or more), nutritional status of children (stunting, underweight, and wasting), age of the child (6-23, 24-42, and 43-59 months), fever (no and yes) or diarrhea (no and yes) within two weeks before the survey, perceived size at birth (small, medium, and large), history of medication (antiparasite in the last 6 months (no and yes) and iron pills/ syrup in the last 7 day (no and yes), and early initiation of breastfeeding (no and yes) were included in the analysis as predicator variables.

3.3. Statistical Analysis. The analysis was carried out using Stata software V14. The data were weighted to adjust for oversampling or undersampling and nonresponses. Descriptive statistics were calculated for all variables. Multicollinearity between independent variables was cheeked before fitting the final regression model. When two independent variables were found highly correlated, one was dropped. Multivariable logistic regression analysis was done to identify factors associated with anemia among children aged 6-59 months. In addition, complex survey analysis techniques were employed when computing odds ratios since EDHS used a two-stage stratified sampling technique. Odds ratios (AOR) with 95\% CI were calculated to measure the strength of association.

\section{Results}

4.1. Sociodemographic Characteristics of Children and Their Mothers. A total of 8,462 children aged 6-59 months were included in the analysis. The mean age of children was 31.7 months with a standard deviation of \pm 0.2 months. About three-fourths of the children were initiated breastfeeding early. About $15 \%$ of the children had a history of fever within two weeks before the study. The majority of the children were from mothers aged 25-34 years. The majority of the children were from rural areas $(89.9 \%)$ and major regions (Amhara, Oromia, SNNPR, and Tigray) (91.1\%) (Table 1).

4.2. Prevalence of Anemia among Children. The prevalence of anemia among children aged 6-59 months was $57.6 \%$ (95\% CI: 55.1, 60.1). Of those, $25.1 \%(23.4,26.8), 29.4 \%(27.4$, $31.6)$, and $3.1 \%(2.4,4.0)$ suffered from mild, moderate, and severe anemia, respectively. Many rural children (58.5\%), whose families belong to poor wealth index (63.0\%), whose mothers with anemic (68.9\%), and young (15-24 years) $(63.0 \%)$, and whose families with high under-five children (>4) (70.4\%), were anemic. Likewise, children whose mothers aged 15-34 years, above one-third (34\%), were subjected to moderate anemia and $5.4 \%$ were with severe anemic. About $37.2 \%$ and $5.6 \%$ of children whose mothers with anemia suffered from moderate and severe anemia, respectively. The anemia prevalence was high among children in the developing regions (74.1\%). About three-fourths of children aged 6-23 months were anemic. From this, $40.9 \%$ and $3.7 \%$ had moderate and severe anemia, respectively. A significant proportion of underweight (64.7\%), stunted $(61.7 \%)$, and wasted $(68.7 \%)$ was anemic at the time of the survey. About $61.4 \%$ and $64.5 \%$ of children with a 
TABLE 1: Sociodemographic characteristics of children and their mothers and prevalence of anemia among children aged 6-59 months in Ethiopia, 2016 EDHS.

\begin{tabular}{|c|c|c|c|c|c|c|}
\hline Variables & Categories & Frequency (\%) & Any anemia (\%) & Mild (\%) & Moderate (\%) & Severe (\%) \\
\hline \multirow{3}{*}{ Age of children in months } & $6-23$ & 34.3 & 72.0 & 27.4 & 40.9 & 3.7 \\
\hline & $24-42$ & 35.2 & 56.5 & 24.1 & 28.5 & 3.9 \\
\hline & $43-59$ & 30.5 & 42.6 & 23.5 & 17.7 & 1.4 \\
\hline \multirow{2}{*}{ Sex } & Male & 51.9 & 57.7 & 24.6 & 29.8 & 3.3 \\
\hline & Female & 48.1 & 57.5 & 25.0 & 29.4 & 3.1 \\
\hline \multirow{2}{*}{ Birth order } & $\leq 5^{\text {th }}$ & 72.5 & 57.0 & 24.8 & 28.9 & 3.3 \\
\hline & $>5^{\text {th }}$ & 27.5 & 59.2 & 25.7 & 30.9 & 2.6 \\
\hline \multirow{3}{*}{ Size of children at birth } & Small & 30.7 & 57.6 & 25.6 & 29.8 & 2.2 \\
\hline & Average & 42.9 & 55.2 & 23.8 & 29.0 & 2.4 \\
\hline & Large & 26.4 & 61.8 & 26.5 & 29.9 & 5.4 \\
\hline \multirow{2}{*}{ Started breastfeeding within $1 \mathrm{hr}$} & No & 24.1 & 56.6 & 26.8 & 26.9 & 2.9 \\
\hline & Yes & 75.9 & 57.9 & 24.6 & 30.2 & 3.1 \\
\hline \multirow{2}{*}{ Underweight } & No & 74.8 & 55.2 & 24.9 & 28.0 & 2.3 \\
\hline & Yes & 25.2 & 64.7 & 25.7 & 33.4 & 5.6 \\
\hline \multirow{2}{*}{ Stunting } & No & 58.9 & 54.3 & 23.9 & 27.9 & 2.5 \\
\hline & Yes & 41.1 & 61.7 & 26.6 & 31.2 & 3.9 \\
\hline \multirow{2}{*}{ Wasting } & No & 90.7 & 56.4 & 25.3 & 28.1 & 3.0 \\
\hline & Yes & 9.3 & 68.7 & 24.2 & 40.6 & 3.9 \\
\hline \multirow{2}{*}{ Had diarrhea } & No & 87.1 & 57.0 & 26.6 & 29.3 & 3.1 \\
\hline & Yes & 12.9 & 61.4 & 28.0 & 30.4 & 3.0 \\
\hline \multirow{2}{*}{ Had fever } & No & 84.8 & 56.4 & 24.3 & 29.0 & 3.1 \\
\hline & Yes & 15.2 & 64.4 & 28.9 & 32.3 & 3.2 \\
\hline \multirow{2}{*}{ Took iron pills/syrup } & No & 90.4 & 57.8 & 25.4 & 29.2 & 3.2 \\
\hline & Yes & 9.6 & 56.1 & 22.3 & 31.4 & 2.4 \\
\hline \multirow{2}{*}{ Received antiparasite } & No & 86.8 & 58.2 & 24.6 & 30.4 & 3.2 \\
\hline & Yes & 13.2 & 54.9 & 28.7 & 23.8 & 2.4 \\
\hline \multirow{3}{*}{ Mother's age } & $15-24$ & 20.7 & 63.0 & 23.6 & 34.0 & 5.4 \\
\hline & $25-34$ & 54.1 & 58.0 & 26.9 & 28.6 & 2.5 \\
\hline & $35-49$ & 25.2 & 52.4 & 22.3 & 27.6 & 2.5 \\
\hline \multirow{2}{*}{ Residence } & Urban & 10.1 & 49.5 & 23.8 & 24.5 & 1.2 \\
\hline & Rural & 89.9 & 58.5 & 25.2 & 30.0 & 3.3 \\
\hline & No education & 67.0 & 58.7 & 24.4 & 30.7 & 3.6 \\
\hline Mother's education status & Primary & 26.9 & 56.9 & 26.9 & 27.7 & 2.2 \\
\hline & Secondary+ & 6.1 & 48.7 & 23.7 & 23.6 & 1.4 \\
\hline Mother's ccunation & No & 72.5 & 58.6 & 25 & 30 & 3.6 \\
\hline Mother's occupation & Yes & 27.5 & 55.0 & 25.2 & 28 & 1.8 \\
\hline & No & 79.6 & 56.6 & 24.8 & 28.8 & 3.0 \\
\hline Mother's BMI & Yes & 20.4 & 60.6 & 25.4 & 31.4 & 3.8 \\
\hline Mother's anemin status & Not anemic & 69.9 & 52.4 & 24.5 & 25.8 & 2.1 \\
\hline Mother's anemia status & Anemic & 30.1 & 68.9 & 26.1 & 37.2 & 5.6 \\
\hline & Not married & 5.1 & 55.9 & 17.7 & 31.7 & 6.5 \\
\hline Mother's marital status & Married & 94.9 & 57.7 & 25.5 & 29.3 & 2.9 \\
\hline & No education & 48.1 & 59.0 & 23.8 & 32.2 & 3.0 \\
\hline Husband's educational status & Primary & 41.0 & 57.3 & 27.5 & 26.8 & 3.0 \\
\hline & Secondary+ & 10.9 & 52.8 & 24.1 & 26.7 & 2.0 \\
\hline Huchond's counotion & No & 7.5 & 61.6 & 23.9 & 34.0 & 3.6 \\
\hline Husband's occupation & Yes & 92.5 & 57.5 & 25.4 & 29.2 & 2.9 \\
\hline & Low & 46.9 & 63.0 & 25.4 & 32.7 & 4.9 \\
\hline Wealth index & Middle & 21.5 & 53.8 & 25.1 & 27.0 & 1.7 \\
\hline & High & 31.6 & 52.1 & 24.4 & 26.3 & 1.4 \\
\hline & Not improved & 44.0 & 58.6 & 24.5 & 30.5 & 3.6 \\
\hline Source of drinking water & Improved & 56.0 & 56.8 & 25.5 & 28.6 & 2.7 \\
\hline & Not improved & 90.5 & 57.7 & 25.1 & 29.5 & 3.1 \\
\hline Toilet type & Improved & 9.5 & 56.4 & 24.7 & 29.0 & 2.7 \\
\hline & $1-4$ & 25.4 & 57.3 & 24.0 & 30.2 & 3.1 \\
\hline Family size & $5-8$ & 61.3 & 56.7 & 25.1 & 28.4 & 3.2 \\
\hline & $9-19$ & 13.3 & 62.4 & 27.1 & 32.5 & 2.8 \\
\hline & $\leq 3$ & 97.4 & 57.3 & 24.9 & 29.3 & 3.1 \\
\hline Number of U5 in the $\mathrm{HH}$ & $\geq 4$ & 2.6 & 70.4 & 32.8 & 34.1 & 3.5 \\
\hline & Developing & 6.6 & 74.1 & 20.2 & 45.3 & 8.6 \\
\hline Region & Major & 91.1 & 56.5 & 25.5 & 28.3 & 2.7 \\
\hline & City administrative & 2.3 & 52.7 & 20.4 & 29.1 & 3.2 \\
\hline
\end{tabular}


history of diarrhea and fever two weeks before the survey were anemic (Table 1).

On multivariable logistic regression analysis, wealth index, region, family size, mother's anemia status and age, stunting, underweight, and history of fever of the child were significantly associated with anemia (hemoglobin level below $11.0 \mathrm{~g} / \mathrm{dl})$. The odds of developing anemia among children of mothers age 15-24 years were 1.4 times higher compared to those of children of mothers age 35-49 years $(\mathrm{AOR}=1.4,95 \% \mathrm{CI}: 1.1,1.8)$. The odds of developing anemia among children who were stunted were 1.3 times higher than those of nonstunted children $(\mathrm{AOR}=1.3,95 \% \mathrm{CI}: 1.1$, 1.6). The odds of developing anemia among children aged 24-42 months and 43-59 months were almost four times $(\mathrm{AOR}=3.8,95 \% \mathrm{CI}: 3.1,4.8)$ and two times $(\mathrm{AOR}=1.7,95 \%$ CI $(1.4,2.1)$ higher compared to those of children aged 43-59 months, respectively. The odds of developing anemia among children who had a history of fever two weeks prior to data collection were 1.3 times higher compared to those of children who did not have fever (AOR $=1.3,95 \% \mathrm{CI}: 1.1,1.7)$ (Table 2).

\section{Discussion}

According to this analysis, about 58\% of children aged 6-59 months were anemic. The prevalence of anemia was higher compared to the previously reported national prevalence estimates. According to the 2005 and 2011 EDHS reports, $54 \%$ and $44 \%$ of children were anemic, respectively $[14,15]$. There was a slight decline in the percentage of children with anemia from 2005 to 2011. However, the proportion increased from 2011 to 2016 . The analysis revealed that about one-third of the children aged 6-59 months had moderate anemia. This was consistent with the 2005 EDHS report. However, it was higher compared to the 2011 EDHS report. The level of severe anemia among children was similar to the two previous EDHS reports $[14,15]$. The reason for the high prevalence of anemia in 2016 compared to the previous EDHS reports could be linked to the drought that affected crop and milk production in most parts of Ethiopia in 2015 and $2016[16,17]$.

The prevalence of anemia was higher among rural children compared to urban. This was consistent with a study performed in Bangladesh [9]. The main reason for the high level of anemia among rural children might be due to the low consumption of iron-containing foods among children in rural areas due to poverty. In addition, poor sanitation and water supplies which lead to a high rate of infection and parasite diseases might be the reasons for the high prevalence of anemia among rural children $[9,18,19]$.

This study showed that anemia was significantly associated with the region. Children living in developing regions were more likely to develop anemia compared to children who were living in city administrates. The findings of previous studies carried out in Ethiopia [10, 20] and India [21] were congruent with this fact. The reason for this might be the variation of environmental, socio-economic, and cultural practices among regions. Mother's age was significantly associated with anemia among children.
TABLE 2: Factors associated with anemia among children aged 6-59 months in Ethiopia, 2016 EDHS.

\begin{tabular}{|c|c|c|c|}
\hline \multicolumn{2}{|l|}{ Variables } & COR $(95 \% \mathrm{CI})$ & AOR $(95 \% \mathrm{CI})$ \\
\hline \multicolumn{4}{|l|}{ Mother's age } \\
\hline \multicolumn{2}{|l|}{$15-24$} & $1.6(1.3,1.9)$ & $1.4(1.1,1.8)^{*}$ \\
\hline \multicolumn{2}{|l|}{$25-34$} & $1.3(1.1,1.5)$ & $1.3(1.1,1.5)^{*}$ \\
\hline \multicolumn{2}{|c|}{$35-49$} & 1 & 1 \\
\hline \multicolumn{4}{|c|}{ Mother's education status } \\
\hline \multicolumn{2}{|c|}{ No education } & $1.5(1.14,2.0)$ & $1.3(0.9,1.8)$ \\
\hline \multicolumn{2}{|l|}{ Primary } & $1.4(1.1,1.8)$ & $1.3(0.9,1.7)$ \\
\hline \multicolumn{2}{|c|}{ Secondary+ } & 1 & 1 \\
\hline \multicolumn{4}{|c|}{ Mother's occupation } \\
\hline \multicolumn{2}{|c|}{ No } & $1.2(1.0,1.4)$ & $1.0(0.9,1.2)$ \\
\hline \multicolumn{2}{|c|}{ Yes } & 1 & 1 \\
\hline \multicolumn{4}{|c|}{ Mother's anemia status } \\
\hline \multicolumn{2}{|c|}{ Not anemic } & 1 & 1 \\
\hline Anemic & $2.0(1.7,2.4)$ & $1.9(1.6,2.2)^{* * *}$ & \\
\hline \multicolumn{4}{|l|}{ Wealth index } \\
\hline Poor & $1.6(1.3,1.9)$ & $1.4(1.1,1.7)^{* *}$ & \\
\hline Middle & $1.1(0.9,1.3)$ & $1.0(0.8,1.2)$ & \\
\hline Rich & 1 & & \\
\hline \multicolumn{4}{|l|}{ Region } \\
\hline Developing & $2.6(1.0,3.3)$ & $1.5(1.1,2.0)^{*}$ & \\
\hline Major & $1.2(0.9,1.5)$ & $0.8(0.6,1.1)$ & \\
\hline $\begin{array}{l}\text { City } \\
\text { administrativ }\end{array}$ & & 1 & \\
\hline \multicolumn{4}{|l|}{ Family size } \\
\hline$\leq 4$ & $1.0(0.9,1.2)$ & $0.9(0.7,1.1)$ & \\
\hline $5-8$ & 1 & 1 & \\
\hline$\geq 9$ & $1.3(1.0,1.5)$ & $1.3(1.1,1.6)^{*}$ & \\
\hline \multicolumn{4}{|c|}{$\begin{array}{l}\text { Number of U5 in } \\
\text { the HH }\end{array}$} \\
\hline$\leq 3$ & 1 & & \\
\hline & $1.8(1.1,3.0)$ & $1.6(0.9,2.7)$ & \\
\hline \multicolumn{4}{|l|}{$\begin{array}{l}\text { Age of child in } \\
\text { months }\end{array}$} \\
\hline $6-23$ & $3.5(2.9,4.2)$ & $3.8(3.1,4.8)^{* * *}$ & \\
\hline $24-42$ & $1.8(1.5,2.1)$ & $1.7(1.4,2.1)^{* * *}$ & \\
\hline $43-59$ & 1 & 1 & \\
\hline \multicolumn{4}{|l|}{ Underweight } \\
\hline No & 1 & 1 & \\
\hline & $1.5(1.3,1.7)$ & $1.3(1.1,1.6)^{*}$ & \\
\hline \multicolumn{4}{|l|}{$\begin{array}{c}\text { Yes } \\
\text { Stunting }\end{array}$} \\
\hline No & 1 & 1 & \\
\hline Yes & $1.4(1.2,1.6)$ & $1.3(1.1,1.6)^{* * *}$ & \\
\hline \multicolumn{4}{|c|}{$1.4(1.2,1.0) 1.0(1.1,1.0)$} \\
\hline No & 1 & & \\
\hline yes & $1.7(1.3,2.2)$ & $1.3(0.9,1.8)$ & \\
\hline Had diarrhea & & & \\
\hline No & 1 & 1 & \\
\hline yes & $1.2(1.0,1.5)$ & $0.9(0.7,1.2)$ & \\
\hline Had fever & & & \\
\hline No & 1 & 1 & \\
\hline Yes & $1.4(1.1,1.7)$ & $1.3(1.1,1.7)^{*}$ & \\
\hline
\end{tabular}

Children from young (15-24 years old) and middle age (25-34 years old) mothers were more likely to be anemic compared to children from older women (35-49 years old). This finding was in line with a study carried out in Brazil $[22,23]$. The reason for this might be poor child care practice among young mothers. Previous studies showed 
that poor child care practices were associated with anemia among children $[12,24]$.

Children from households with large family sizes were more likely to be anemic compared to children from households with smaller family sizes. Inadequate intake of nutrients might be the reason for higher odds of anemia among children from households with large family size. In this analysis, children from households with poor wealth index had higher odds of being anemic compared to children from rich households. This finding was congruent with studies carried out in Ethiopia [10, 11, 20], Brazil [25], Switzerland [26], Burma [27], and India [28]. The reasons for this might be low nutrition uptake among children from households with poor wealth index. Children from low socioeconomic families are more likely to be malnourished, which may aggravate anemia.

Maternal anemia was significantly associated with anemia among children. The odds of developing anemia among children whose mothers were anemic was higher compared to those of children whose mothers were not anemic. This finding was in line with studies carried out in Togo [29], Brazil [30, 31], Kuwait [32], and Nepal [33]. This could be explained by the fact that these children share a common environment and socioeconomic and dietary conditions with the mother.

This study showed that stunted children were more likely to develop anemic compared to children who were not stunted. This finding was supported by other studies conducted in Ethiopia [11, 20], India [26], Bangladesh [34], Haiti [35], Brazil [22], and Burma [27]. The reason for this is that the stunted children in Ethiopia are more likely to have micronutrient deficiencies [22].

The odds of developing anemia among children aged 24-42 months and 43-59 months was higher compared to those of children aged 43-59 months. This finding was in line with previous studies carried out in Ethiopia [10], Togo [29], Bangladesh [9, 36], Brazil [22, 31], Haiti [35], Asia and India [21], Burma [27], Sydney [37], and Nepal [33]. Growing children have a higher demand for micronutrients. Failure to meet this demand may lead to anemia among children. The other reason might be that older children receive a diet that is rich and sufficient in iron as a result of a more varied diet, which could prevent the occurrence of anemia. According to this study, children who had a history of fever two weeks prior to data collection were more likely to be anemic compared to children who did not have fever. This finding was in line with previous studies [9, 26]. The reason for this might be hemolysis of red blood cells that can be caused by febrile diseases like malaria. Inadequate food intake due to loss of appetite during the febrile period may be the other reason.

\section{Conclusion}

The prevalence of anemia among children in Ethiopia was high. Children whose mothers were anemic and children from young mothers had more odds of developing anemia. Children from poor households were also more likely to be anemic. Stunted, younger, and underweight children and children with a history of fever had higher odds of developing anemia. The Ministry of Health with other collaborators should design interventions to prevent maternal anemia and childhood illness (stunting, underweight, and fever).

\section{Data Availability}

The DHS data analyzed during the current study are available in the repository (https://dhsprogram.com/data).

\section{Ethical Approval}

The protocol for the 2016 EDHS was approved by the Institutional Review Board (IRB) of ICF and the National Ethics Review Committee at the Ministry of Science and Technology. The authors obtained permission from the DHS program to download and use the data for this analysis.

\section{Conflicts of Interest}

The authors declare that they have no conflicts of interest.

\section{Acknowledgments}

The authors would like to thank the DHS program for allowing using the data for this analysis.

\section{References}

[1] World Health Organization (WHO), Iron Deficiency Anemia. Assessment, Prevention, and Control. A Guide for Program Managers, World Health Organization (WHO), Geneva, Switzerland, 2001.

[2] B. J. Brabin, M. Hakimi, and D. Pelletier, "Iron-deficiency anemia: reexamining the nature and magnitude of the public health problem," Journal of Nutrition, vol. 131, pp. 6045-6155, 2001.

[3] G. A. Stevens, M. M. Finucane, L. M. De-Regil et al., "Global, regional, and national trends in haemoglobin concentration and prevalence of total and severe anaemia in children and pregnant and non-pregnant women for 1995-2011: a systematic analysis of population-representative data," The Lancet Global Health, vol. 1, no. 1, pp. e16-e25, 2013.

[4] S. Grantham-McGregor and C. Ani, "A review of studies on the effect of iron deficiency on cognitive development in children," The Journal of Nutrition, vol. 131, no. 2, pp. 649S-668S, 2001.

[5] B. Lozoff, E. Jimenez, and A. W. Wolf, "Long-term developmental outcome of infants with iron deficiency," New England Journal of Medicine, vol. 325, no. 10, pp. 687-694, 1991.

[6] E. Pollitt, "Iron deficiency and cognitive function," Annual Review of Nutrition, vol. 13, no. 1, pp. 521-537, 1993.

[7] M. Cornet, M. Cot, N. Fievet et al., "Prevalence of and risk factors for anemia in young children in southern Cameroon," The American Journal of Tropical Medicine and Hygiene, vol. 58 , no. 5, pp. $606-611,1998$.

[8] A. F. Fleming and B. Werblińska, "Anaemia in childhood in the Guinea savanna of Nigeria," Annals of Tropical Paediatrics, vol. 2, no. 4, pp. 161-173, 1982.

[9] J. R. Khan, N. Awan, and F. Misu, "Determinants of anemia among 6-59 months aged children in Bangladesh: evidence 
from nationally representative data," BMC Pediatrics, vol. 16, no. 1, p. 3, 2016.

[10] K. N. Kawo, Z. G. Asfaw, and N. Yohannes, "Multilevel analysis of determinants of anemia prevalence among children aged 6-59 months in Ethiopia: classical and bayesian approaches," Anemia, vol. 2018, Article ID 3087354, 13 pages, 2018.

[11] H. Woldie, Y. Kebede, and A. Tariku, "Factors associated with anemia among children aged 6-23 months attending growth monitoring at Tsitsika Health Center, Wag-Himra Zone, Northeast Ethiopia," Journal of Nutrition and Metabolism, vol. 2015, Article ID 928632, 9 pages, 2015.

[12] B. G. Malako, M. S. Teshome, and T. Belachew, "Anemia and associated factors among children aged 6-23 months in Damot Sore District, Wolaita Zone, South Ethiopia," BMC Hematology, vol. 18, no. 1, p. 14, 2018.

[13] Ethiopian Demographic Health Survey (EDHS), Ethiopian Demographic and Health Survey 2016: Key Indicators Report. The DHS Program ICF, Ethiopian Demographic Health Survey (EDHS), Addis Ababa, Ethiopia, 2016.

[14] Central Statistical Agency and ORC Macro, Ethiopia Demographic and Health Survey, Central Statistical Agency, Addis Ababa, Ethiopia, 2011.

[15] Central Statistical Agency and ORC Macro, Ethiopia Demographic and Health Survey, Central Statistical Agency, Addis Ababa, Ethiopia, 2005.

[16] C. Funk, P. Peterson, M. Landsfeld et al., "The climate hazards infrared precipitation with stations-a new environmental record for monitoring extremes," Scientific Data, vol. 2, no. 1, p. 150066, 2015.

[17] S. Philip, S. F. Kew, G. Jan van Oldenborgh et al., "Attribution analysis of the Ethiopian drought of 2015," Journal of Climate, vol. 31, no. 6, pp. 2465-2486, 2018.

[18] J. F. Gonçalves, M. Tanabe, F. d. P. d. M. Medeiros et al., "Parasitological and serological studies on amoebiasis and other intestinal parasitic infections in the rural sector around Recife, Northeast Brazil," Revista do Instituto de Medicina Tropical de São Paulo, vol. 32, no. 6, pp. 428-435, 1990.

[19] World Health Organization (WHO), Preventing and Controlling Iron Deficiency Anemia through Primary Health Care: A Guide for Health Administrators and Program Managers, World Health Organization (WHO), Geneva, Switzerland, 1989.

[20] G. Gebreegziabiher, B. Etana, and D. Niggusie, "Determinants of anemia among children aged 6-59 months living in Kilte Awulaelo Woreda, Northern Ethiopia," Anemia, vol. 2014, Article ID 245870, 9 pages, 2014.

[21] P. Kotecha, "Nutritional anemia in young children with focus on Asia and India," Indian Journal of Community Medicine, vol. 36, no. 1, p. 8, 2011.

[22] M. M. Osório, P. I. C. Lira, M. Batista-Filho, and A. Ashworth, "Prevalence of anemia in children 6-59 months old in the state of Pernambuco, Brazil," Revista Panamericana de Salud Pública, vol. 10, no. 2, pp. 101-107, 2001.

[23] T. Konstantyner, J. A. A. C. Taddei, M. N. Oliveira, D. Palma, and F. A. B. Colugnati, "Isolated and combined risks for anemia in children attending the nurseries of daycare centers," Jornal de Pediatria, vol. 85, no. 3, pp. 209-216, 2009.

[24] H. Dalili, A. Baghersalimi, S. Dalili et al., "Is there any relation between the duration of breastfeeding and anemia?" Iranian Journal of Pediatric Hematology and Oncology, vol. 5, no. 4, p. 218, 2015.

[25] P. T. Muniz, T. G. D. Castro, T. S. D. Araújo et al., "Child health and nutrition in the Western Brazilian Amazon: population-based surveys in two counties in Acre State," Cadernos de Saúde Pública, vol. 23, no. 6, pp. 1283-1293, 2007.

[26] A. Prieto-Patron, K. Van der Horst, Z. Hutton, and P. Detzel, "Association between anaemia in children 6 to 23 months old and child, mother, household and feeding indicators," $\mathrm{Nu}$ trients, vol. 10, no. 9, p. 1269, 2018.

[27] A. Zhao, Y. Peng, J. Li et al., "Prevalence of anemia and its risk factors among children 6-36 months old in Burma," The American Journal of Tropical Medicine and Hygiene, vol. 87, no. 2, pp. 306-311, 2012.

[28] S.-R. Pasricha, J. Black, S. Muthayya et al., "Determinants of anemia among young children in rural India," Pediatrics, vol. 126, no. 1, pp. e140-e149, 2010.

[29] A. Nambiema, A. Robert, and I. Yaya, "Prevalence and risk factors of anemia in children aged from 6 to 59 months in Togo: analysis from Togo demographic and health survey data, 2013-2014," BMC Public Health, vol. 19, no. 1, p. 215, 2019.

[30] M. S. Leite, A. M. Cardoso, C. E. Coimbra et al., "Prevalence of anemia and associated factors among indigenous children in Brazil: results from the First National Survey of Indigenous People's Health and Nutrition," Nutrition Journal, vol. 12, no. 1, p. 69, 2013.

[31] L. P. Leal, M. Batista Filho, P. I. C. D. Lira, J. N. Figueiroa, and M. M. Osório, "Prevalência da anemia e fatores associados em crianças de seis a 59 meses de Pernambuco," Revista de Saúde Pública, vol. 45, no. 3, pp. 457-466, 2011.

[32] N. M. Al-Qaoud, E. Al-Shami, and P. Prakash, "Anemia and associated factors among Kuwaiti preschool children and their mothers," Alexandria Journal of Medicine, vol. 51, no. 2, pp. 161-166, 2015.

[33] V. Khanal, R. Karkee, M. Adhikari, and T. Gavidia, "Moderate-to-severe anemia among children aged 6-59 months in Nepal: an analysis from Nepal demographic and health survey, 2011," Clinical Epidemiology and Global Health, vol. 4, no. 2, pp. 57-62, 2016.

[34] R. D. Merrill, A. A. Shamim, H. Ali et al., "High prevalence of anemia with lack of iron deficiency among women in rural Bangladesh: a role for thalassemia and iron in groundwater," Asia Pacific Journal of Clinical Nutrition, vol. 21, no. 3, pp. 416-424, 2012.

[35] M. A. Ayoya, I. Ngnie-Teta, M. N. Séraphin et al., "Prevalence and risk factors of anemia among children 6-59 months old in Haiti," Anemia, vol. 2013, Article ID 502968, 3 pages, 2013.

[36] M. K. Uddin, M. H. Sardar, M. Z. Hossain et al., "Prevalence of anemia in children of 6 months to 59 months in Narayanganj, Bangladesh," Journal of Dhaka Medical College, vol. 19, no. 2, pp. 126-130, 1970.

[37] M. Karr, G. Alperstein, J. Causer, M. Mira, A. Lammi, and M. J. Fett, "Iron status and anaemia in preschool children in Sydney," Australian and New Zealand Journal of Public Health, vol. 20, no. 6, pp. 618-622, 1996. 